\title{
Precarious Employment and Increased Incidence of Musculoskeletal Pain among Wage Workers in Korea: A Cross-Sectional Study
}

\author{
Sungjin Park ${ }^{1}\left(\mathbb{D}\right.$ and June-Hee Lee ${ }^{2, *}$ (]) \\ 1 Department of Occupational and Environmental Medicine, Cheonan Medical Center, Cheonan 31151, Korea; \\ psjin9318@gmail.com \\ 2 Department of Occupational and Environmental Medicine, Soonchunhyang University College of Medicine, \\ Seoul 04401, Korea \\ * Correspondence: junelee@schmc.ac.kr; Tel.: +82-02-709-9452
}

check for

updates

Citation: Park, S.; Lee, J.-H.

Precarious Employment and

Increased Incidence of

Musculoskeletal Pain among Wage

Workers in Korea: A Cross-Sectional

Study. Int. J. Environ. Res. Public

Health 2021, 18, 6299. https://

doi.org/10.3390/ijerph18126299

Academic Editor: Kyung-Eun (Anna) Choi

Received: 10 May 2021

Accepted: 8 June 2021

Published: 10 June 2021

Publisher's Note: MDPI stays neutral with regard to jurisdictional claims in published maps and institutional affiliations.

Copyright: (C) 2021 by the authors. Licensee MDPI, Basel, Switzerland. This article is an open access article distributed under the terms and conditions of the Creative Commons Attribution (CC BY) license (https:/ / creativecommons.org/licenses/by/ $4.0 /)$.

\begin{abstract}
The number of precarious workers is increasing globally, and precarious employment is becoming a public concern in terms of workers' health. However, sufficient research on precarious employment and its impact on musculoskeletal pain (MSP) is lacking. This study aimed to investigate the relationship between precarious employment and the risk of MSP among Korean wage workers. After merging the data from the 4th and 5th Korean Working Conditions Surveys, 59,644 wage workers were analyzed. The control group comprised full-time permanent workers, and precarious employment was defined as workers involved in temporary or daily employment, or part-time workers. The outcome variable was the summed number of MSP in three anatomical sites (back, neck and upper limb, lower limb). Zero-inflated negative binomial analyses were selected to estimate the odds ratios (ORs) and 95\% confidence intervals (CIs) between precarious employment and MSP. In adjusted models with age, sex, educational level, income level, weekly working hours, and occupation, precarious employment was significantly associated with an increased risk of both MSP (OR 1.66 95\% CI 1.56-1.77) and work-related MSP (OR 1.18 95\% CI 1.11-1.25). Given the job insecurity and health inequity associated with precarious employment, special attention on precarious workers' health is needed.
\end{abstract}

Keywords: musculoskeletal disorders; employees; non-standard employment; working conditions; occupational health

\section{Introduction}

Precarious employment is a collective term that refers to a set of labor market working conditions that are disadvantageous to workers [1]. Although there is no overall consensus regarding a precise definition of the term, precarious employment is often considered to be characterized by temporary employment, income insufficiency, and lack of social protection or worker rights [2-4]. Economic globalization, which emerged in the late 1900s, led to intense changes in the labor market seeking more flexible employment [5]. This accelerated the transition from standard employment, characterized by permanent and full-time contracts, to non-standard or atypical types of employment [6]. During the last few decades, the number of workers in precarious employment has grown in many developed countries, including the US, Europe, and Korea [7,8]. In 2019, the combined proportion of daily and temporary employment was estimated to be $21.7 \%$ among the economically active population in Korea [9].

Precarious employment is associated with the ill health of workers because of its poor working conditions. The health-related outcomes of precarious employment are mainly the effects on general [10-12] and mental health [13-17] and physical injuries [18]. However, the relationship between precarious employment and physical complaints such as musculoskeletal pain (MSP) has received relatively less attention. 
MSP can have direct physical or psychological impacts on individuals [19]. In both developed and developing countries, MSP is a fairly common cause of disability [20] and is one of the most common work-related medical conditions [21]. Moreover, MSP in two or more anatomical sites is not uncommon and is more severe than MSP in single sites [21].

Therefore, more evidence regarding the association between precarious employment and the risk of increased incidence of MSP is required. This study aimed to investigate the relationship, using large-scale national data representing Korean workers. Particularly, the analysis focused on the association between the risk of increased incidence of MSP in multiple body parts and precarious employment. Further, we specifically considered three individual sites—back, the neck and upper limbs, and lower limbs.

\section{Methods}

\subsection{Study Design and Participants}

This cross-sectional study is based on a secondary analysis of data from the 4th (2014) and 5th (2017) Korean Working Conditions Survey (KWCS) conducted by the Korean Occupational Safety and Health Agency. KWCS gathers information on work environments, exposure to risk factors for workers' health, and health outcomes. The survey population is representative of economically active working adults, and thus, retirees, the unemployed, housewives, and students were excluded from the study sample. Participants were extracted from multistage, stratified, random sampling from the census and interviewed face-to-face. The reliability and validity of the KWCS data have been confirmed in previous studies [22].

Initially, merging the 4th and 5th KWCS produced the data of 100,212 workers in total, of whom 60,859 were wage workers. After excluding 302 subjects with missing MSP values and 913 with no information on the type of employment, 59,644 wage workers were included in the final analysis.

\subsection{Measurements}

Precarious Employment

Participants responded to questions regarding the type of employment (permanent, temporary, or daily) and work schedule (full-time or part-time) associated with their current job. Based on these two criteria, precarious employment was defined as either having temporary or daily employment or working part-time. Workers not falling into this category were regarded as full-time permanent workers.

\subsection{Musculoskeletal Pain and Work-Related MSP}

MSP and work-related MSP (or WMSP) were defined by two questions regarding the prevalence of MSP and whether they were related to work. First, participants responded to self-reported questions about MSP in their body parts such as the back, upper limbs and neck, and lower limbs during the last year. If they had any MSP, they answered further, whether they perceived it as work-related. Additionally, the summed number of MSP in the three body parts was produced as an outcome variable.

\subsection{Covariates}

The models of this study included a range of covariates, including sex, age (20-29, $30-39,40-49,50-59,60$ or older), educational level (under high school, high school, above high school), income level (less than 2 million Korean Won, 2 million Korean Won or more), working hours per week (40 or less, 41-52, 53-60, more than 60), occupations, and ergonomic risk factors at the workplace. The occupations were classified into office work (management, professional, or clerical work), service or sales work, and manual work (skilled work related to agriculture, forestry, and fisheries; craft and trade work; equipment, machine operating, and assembling or elementary work). For ergonomic risk factors, exposure for more than half of the working hours to any of the following five risk factors was defined as having exposure: fatigue-inducing or painful posture; lifting or moving 
people; dragging, pushing, or moving heavy objects; a standing posture; and repetitive hand or arm movements.

\subsection{Statistical Analysis}

Chi-square tests were conducted to understand the relationship between precarious employment, demographic, socioeconomic, and occupational characteristics and MSP of employees. Both MSP and WMSP are count variables with a range of $0-3$ and a skewed distribution to zero, giving them a greater variance than the average value. Zero-inflated negative binomial regression (ZINBR) was selected as the optimum model after comparing the goodness-of-fit of Poisson regression, negative binomial regression (NBR), and ZINBR, which are suitable analytical methods for these variables. The association between precarious employment and the risk of increased incidence of MSP or WMSP was investigated using ZINBR. All analyses were performed using SPSS 26 (IBM Corp, Armonk, NY, USA), and $p$-values $<0.05$ were considered statistically significant.

\section{Results}

Table 1 shows the demographic, socio-economic, and work-related characteristics of the study participants. Approximately a quarter (27.29\%) were working in precarious employment. All variables such as age group, sex, educational and income level, weekly working hours, occupation, and ergonomic risk factors were significantly associated with precarious employment. Compared to full-time permanent workers, precarious workers were primarily women, aged 50 or older, had lower levels of education and income, and were engaged in manual work than office work. The proportion of being exposed to five harmful ergonomic risk factors was remarkably higher in precarious workers than in full-time permanent workers (fatigue-inducing or painful posture; lifting or moving people, dragging, pushing, or moving heavy objects, standing posture, repetitive hand or arm movements).

Table 1. General characteristics and working conditions by precarious employment.

\begin{tabular}{|c|c|c|c|}
\hline \multirow{2}{*}{ Characteristics } & \multicolumn{2}{|c|}{ Precarious Employment } & \multirow{2}{*}{$p$-Value } \\
\hline & No [n (\%)] & Yes $[n(\%)]$ & \\
\hline Total & $43,368(72.71)$ & $16,276(27.29)$ & \\
\hline \multicolumn{4}{|l|}{ Age } \\
\hline $20-29$ & $5112(11.79)$ & $2734(16.80)$ & $<0.0001$ \\
\hline $30-39$ & $12,253(28.25)$ & $1683(10.34)$ & \\
\hline $40-49$ & $13,163(30.35)$ & $2980(18.31)$ & \\
\hline $50-59$ & $9299(21.44)$ & $3711(22.80)$ & \\
\hline 60 or above & $3541(8.17)$ & $5168(31.75)$ & \\
\hline \multicolumn{4}{|l|}{ Sex } \\
\hline Men & $23,347(53.83)$ & $6287(38.63)$ & $<0.0001$ \\
\hline Women & $20,021(46.17)$ & 9989 (61.37) & \\
\hline \multicolumn{4}{|l|}{ Educational level } \\
\hline Middle school or lower & $2454(5.68)$ & $5093(31.50)$ & $<0.0001$ \\
\hline High school & $14,145(32.73)$ & 7571 (46.82) & \\
\hline College or higher & $26,619(61.59)$ & $3506(21.68)$ & \\
\hline Income level & & & $<0.0001$ \\
\hline$\geq 2,000,000$ Won & $31,179(72.22)$ & $5238(32.31)$ & \\
\hline$<2,000,000$ Won & $11,992(27.78)$ & $10,976(67.69)$ & \\
\hline \multicolumn{4}{|l|}{ Weekly working hours } \\
\hline$\leq 40$ & $23,000(53.03)$ & $10,914(67.06)$ & $<0.0001$ \\
\hline $4 \overline{1}-52$ & $13,202(30.44)$ & $2966(18.22)$ & \\
\hline $53-60$ & $5230(12.06)$ & $1568(9.63)$ & \\
\hline$>60$ & $1936(4.46)$ & $828(5.09)$ & \\
\hline \multicolumn{4}{|l|}{ Occupation } \\
\hline Office workers & $21,711(50.28)$ & $1984(12.21)$ & $<0.0001$ \\
\hline
\end{tabular}


Table 1. Cont.

\begin{tabular}{cccc}
\hline \multirow{2}{*}{ Characteristics } & \multicolumn{2}{c}{ Precarious Employment } & \multirow{2}{*}{$p$-Value } \\
\cline { 2 - 3 } & No [n (\%)] & Yes [n (\%)] & \\
\hline Service workers & $10,694(24.76)$ & $6059(37.28)$ & \\
Manual workers & $10,778(24.96)$ & $8210(50.51)$ & \\
Exposure to risk factors for more than half & & & \\
of working time & & & \\
Fatigue-inducing or painful posture & $11,786(27.22)$ & $6415(39.54)$ & $<0.0001$ \\
Lifting or moving people & $2260(5.23)$ & $1089(6.72)$ & $<0.0001$ \\
Dragging, pushing, or moving heavy objects & $5985(13.84)$ & $3695(22.77)$ & $<0.0001$ \\
$\quad$ Standing posture & $17,630(40.76)$ & $10,011(61.75)$ & $<0.0001$ \\
Repetitive hand or arm movements & $22,324(51.66)$ & $9841(60.70)$ & $<0.0001$ \\
\hline
\end{tabular}

All $p$-values are produced from chi-square tests conducted on the 4-5th KWCS data.

Table 2 shows the significant relationship between precarious employment and MSP (WMSP). The proportion of having any MSP, having two or three MSP in multiple sites, and the average numbers of MSP were significantly higher in precarious workers than in full-time permanent workers. This result was the same for WMSP. Precarious workers had a significantly higher prevalence of back pain, neck and upper limb pain, and lower limb pain than full-time permanent workers (data not shown).

Table 2. Number of musculoskeletal pain by precarious employment.

\begin{tabular}{cccc}
\hline Characteristics & \multicolumn{2}{c}{ Precarious Employment } & \multirow{2}{*}{$p$-Value } \\
\cline { 2 - 3 } & No [n (\%)] & Yes [n (\%)] & \\
\hline Number of musculoskeletal pain & & & \\
0 & $29,937(69.03)$ & $9135(56.13)$ & $<0.0001$ \\
1 & $6636(15.30)$ & $2520(15.48)$ & \\
2 & $4682(10.80)$ & $2780(17.08)$ & \\
3 & $2113(4.87)$ & $1841(11.31)$ & \\
Number of work-related musculoskeletal & & & \\
pain & & & \\
0 & $32,048(73.90)$ & $10,820(66.48)$ & $<0.0001$ \\
1 & $7112(16.18)$ & $2089(12.38)$ & \\
2 & $5082(11.56)$ & $2112(12.98)$ & \\
3 & $1934(4.4)$ & $1255(7.71)$ & $<0.0001$ \\
Average number of musculoskeletal pain * & $0.51 \pm 0.87$ & $0.83 \pm 1.08$ & $<0.0001$ \\
Average number of work-related & $0.43 \pm 0.82$ & $0.62 \pm 0.98$ & \\
musculoskeletal pain * & & & \\
\hline * Mean \pm standard deviation. & &
\end{tabular}

Table 3 shows the odds ratios (ORs) and 95\% confidence intervals (CIs) from the ZIBNR analysis. After adjusting for age group, sex, educational level, income level, working hours, and occupation, the risk of increased incidence of MSP was significantly higher in precarious workers than full-time permanent workers (OR 1.66 95\% CI 1.56-1.77). Although the magnitude of risk was slightly lower, the OR of increased incidence of WMSP also showed a significant increase in precarious employment (OR 1.18 95\% CI 1.11-1.25). 
Table 3. Increased incidence of musculoskeletal pain and precarious employment from the zeroinflated negative binomial regression analyses.

\begin{tabular}{ccc}
\hline Outcome & Crude & Adjusted $^{\text {a }}$ \\
\cline { 2 - 3 } & OR (95\% CI) & OR (95\% CI) \\
\hline Increased incidence of musculoskeletal pain \\
Precarious employment \\
No & & \\
Yes & 1.00 (reference) & 1.00 (reference) \\
Increased incidence of work-related musculoskeletal pain & $2.09(1.98-2.20)$ & $1.66(1.56-1.77)$ \\
Precarious employment & & \\
No & & \\
Yes & 1.00 (reference) & 1.00 (reference) \\
& $1.55(1.47-1.62)$ & $1.18(1.11-1.25)$ \\
\hline
\end{tabular}

OR, odds ratio; CI, confidence interval. ${ }^{a}$ Adjusted for age group, sex, educational level, income level, weekly working hours, and occupation.

\section{Discussion}

This study identified findings based on nationally representative data with large samples of Korean wage workers. The risk of an increase in the incidence of MSP as well as WMSP was significantly elevated in precarious workers compared to full-time permanent workers.

Our results are consistent with that of several previous studies. In studies using only the 5th KWCS, the risk of MSP such as back pain, upper limb pain, and lower limb pain was significantly higher among daily workers than standard workers [5]; it was also higher among nonstandard males who are unskilled manual workers, compared to other occupational categories [17]. Moreover, two recent studies which measured multidimensional aspects of precarious employment also suggested that precarious workers had an increased risk of having MSP in more than one area [23], and increased risk of back pain, upper limb pain, and lower limb pain [24]. However, in a study using the same methods of measuring multiple dimensions of precarious employment [25], no significant association was observed between precarious employment and MSP. A plausible reason for this inconsistent result could be that the control group in that study was a low precarious group, whereas the control group in the other studies comprised regular or full-time permanent workers. Another reason suggested by the researchers might be that the workers in the highly precarious group were younger than those in the less precarious group and presumably more resistant when it comes to MSP.

Several explanations have been provided for the relationship between precarious employment and health inequity $[26,27]$. Direct and psychological effects stem from an uncertain future, unfairness, and the powerlessness of precarious employment. Contrastingly, indirect causes include the lack of material or social resources and more chances to be exposed to harmful physical or psychological working conditions.

Similarly, various hypotheses can be put forward about the relationship between precarious employment and MSP. The results of this study revealed that precarious workers tend to be older, manual workers with greater exposure to ergonomically inappropriate working factors $[5,21]$. Aging decreases physical ability, flexibility, and muscle strength, making the body vulnerable to injuries, which can increase physical complaints such as MSP [28]. Additionally, social or material deprivation due to precarious employment can restrict the resources required for physical activity [29,30], contributing to lack of exercise and reduction in muscle strength, which is a risk factor for MSP [31,32].

This study is not without its limitations. First, caution must be exercised when establishing causality because of the cross-sectional study design. Researchers have proposed the possibility of reverse causation between precarious employment and ill health, namely the "healthy hire effect" - a hypothesis that healthier workers are employed and remain in full-time permanent work [25]. However, others have suggested that the negative impact of precarious employment on workers' health is more reasonable [33]. Further studies based on a sufficient sample size will be needed to establish causality. Second, recent studies on 
precarious employment and MSP have used multidimensional constructs of precarious employment rather than single indicators, such as types of employment [23,24]. However, the evaluation of precarious employment using a type of employment or contract, such as temporary or part-time work, is a widely used method in epidemiological settings [25]. Additionally, our study defined workers as being in precarious employment if they had either temporary or part-time jobs. In other words, this is an effort to be in line with existing studies, where workers could be classified into the highly precarious group if the score of any one specific dimension of several constructs of precarious employment was high [34]. In the future, detailed characteristics of precarious employment should be measured to study its health effects.

\section{Conclusions}

Despite these drawbacks, this study clearly revealed that precarious employment is associated with the risk of increased incidence of not only MSP in general but also MSP related to occupational causes. Considering the unfairness and health inequity in precarious employment, special attention and efforts to improve workers' health are necessary.

Author Contributions: Conceptualization, S.P. and J.-H.L.; methodology, S.P. and J.-H.L.; formal analysis, J.-H.L.; investigation, S.P.; data curation, S.P.; writing—original draft preparation, S.P.; writing - review and editing, S.P. and J.-H.L.; visualization, S.P.; supervision, J.-H.L.; project administration, J.-H.L.; funding acquisition, J.-H.L. All authors have read and agreed to the published version of the manuscript.

Funding: This work was supported by the Soonchunhyang University Research Fund. This funding body did not have any role in the design of this study and collection, analysis, and interpretation of data and in writing the manuscript.

Institutional Review Board Statement: Ethical review and approval were waived for this study, because KWCS data is secondary and public data and KWCS comprises national open-source data with safeguards to protect the participants' anonymity and privacy rights.

Informed Consent Statement: Informed consent was obtained from all subjects involved in the KWCS.

Data Availability Statement: KWCS data can be found and downloaded publicly at the following link: https:/ / oshri.kosha.or.kr/eoshri/resources/KWCSDownload.do.

Acknowledgments: The authors are grateful to the Occupational Safety and Health Research Institute (OSHRI) and the Korea Occupational Safety and Health Agency (KOSHA) for providing the raw data from the KWCS.

Conflicts of Interest: The authors declare that there are no conflict of interest.

\section{References}

1. Porthé, V.; Ahonen, E.; Vázquez, M.L.; Pope, C.; Agudelo, A.A.; García, A.M.; Amable, M.; Benavides, F.G.; Benach, J. ITSAL Project. Extending a model of precarious employment: A qualitative study of immigrant workers in Spain. Am. J. Ind. Med. 2010, 53, 417-424. [CrossRef] [PubMed]

2. Kreshpaj, B.; Orellana, C.; Burström, B.; Davis, L.; Hemmingsson, T.; Johansson, G.; Kjellberg, K.; Jonsson, J.; Wegman, D.H.; Bodin, T. What is precarious employment? A systematic review of definitions and operationalizations from quantitative and qualitative studies. Scand. J. Work Environ. Health 2020, 46, 235-247. [CrossRef] [PubMed]

3. Bodin, T.; Çağlayan, Ç.; Garde, A.H.; Gnesi, M.; Jonsson, J.; Kiran, S.; Kreshpaj, B.; Leinonen, T.; Mehlum, I.S.; Nena, E.; et al. Precarious employment in occupational health-An OMEGA-NET working group position paper. Scand. J. Work Environ. Health 2020, 46, 321-329. [CrossRef]

4. Vives, A.; Amable, M.; Ferrer, M.; Moncada, S.; Llorens, C.; Muntaner, C.; Benavides, F.G.; Benach, J. Employment precariousness and poor mental health: Evidence from Spain on a new social determinant of health. J. Environ. Public Health 2013, $2013,978656$. [CrossRef] [PubMed]

5. Park, J.; Kim, Y. Factors related to physical and mental health in workers with different categories of employment. J. Occup. Environ. Med. 2020, 62, 511-518. [CrossRef]

6. Bosch, G. Towards a new standard employment relationship in Western Europe. Br. J. Ind. Relat. 2004, 42, 617-636. [CrossRef]

7. Lee, H.E.; Kawachi, I. Association between unpredictable work schedules and depressive symptoms in Korea. Saf. Health Work 2021. [CrossRef] 
8. Bahk, J.; Khang, Y.H.; Lim, S. The unequal burden of self-reported musculoskeletal pains among South Korean and European employees based on age, gender, and employment status. Saf. Health Work 2021, 12, 57-65. [CrossRef]

9. Park, J.; Kim, Y. From workers to the working-age population: A new paradigm for the occupational health service. Saf. Health Work 2019, 10, 251-253. [CrossRef]

10. Julià, M.; Vanroelen, C.; Bosmans, K.; Van Aerden, K.; Benach, J. Precarious employment and quality of employment in relation to health and well-being in Europe. Int. J. Health Serv. 2017, 47, 389-409. [CrossRef]

11. Van Aerden, K.; Puig-Barrachina, V.; Bosmans, K.; Vanroelen, C. How does employment quality relate to health and job satisfaction in Europe? A typological approach. Soc. Sci. Med. 2016, 158, 132-140. [CrossRef] [PubMed]

12. Kim, M.H.; Kim, C.Y.; Park, J.K.; Kawachi, I. Is precarious employment damaging to self-rated health? Results of propensity score matching methods, using longitudinal data in South Korea. Soc. Sci. Med. 2008, 67, 1982-1994. [CrossRef] [PubMed]

13. Julià, M.; Vives, A.; Tarafa, G.; Benach, J. Changing the way we understand precarious employment and health: Precarisation affects the entire salaried population. Saf. Sci. 2017, 100, 66-73. [CrossRef]

14. Min, K.B.; Park, S.G.; Song, J.S.; Yi, K.H.; Jang, T.W.; Min, J.Y. Subcontractors and increased risk for work-related diseases and absenteeism. Am. J. Ind. Med. 2013, 56, 1296-1306. [CrossRef]

15. Ahn, J.; Kim, N.-S.; Lee, B.-K.; Park, J.; Kim, Y. Non-standard workers have poorer physical and mental health than standard workers. J. Occup. Environ. Med. 2019, 61, e413-e421. [CrossRef] [PubMed]

16. De Moortel, D.; Vandenheede, H.; Vanroelen, C. Contemporary employment arrangements and mental well-being in men and women across Europe: A cross-sectional study. Int. J. Equity Health 2014, 13, 90. [CrossRef]

17. Park, J.; Han, B.; Park, J.-S.; Park, E.J.; Kim, Y. Nonstandard workers and differential occupational safety and health vulnerabilities. Am. J. Ind. Med. 2019, 62, 701-715. [CrossRef]

18. Virtanen, M.; Kivimäki, M.; Joensuu, M.; Virtanen, P.; Elovainio, M.; Vahtera, J. Temporary employment and health: A review. Int. J. Epidemiol. 2005, 34, 610-622. [CrossRef]

19. Yiengprugsawan, V.S.; Piggott, J.; Witoelar, F.; Blyth, F.M.; Cumming, R.G. Pain and its impact on functional health: 7-year longitudinal findings among middle-aged and older adults in Indonesia. Geriatrics 2020, 5, 39. [CrossRef]

20. GBD 2017 Disease and Injury Incidence and Prevalence Collaborators. Global, regional, and national incidence, prevalence, and years lived with disability for 354 diseases and injuries for 195 countries and territories, 1990-2017: A systematic analysis for the Global Burden of Disease Study 2017. Lancet 2018, 392, 1789-1858. [CrossRef]

21. Park, S.; Lee, J.; Lee, J.-H. Insufficient rest breaks at workplace and musculoskeletal disorders among Korean kitchen workers. Saf. Health Work 2021. [CrossRef]

22. Kim, Y.S.; Rhee, K.Y.; Oh, M.J.; Park, J. The validity and reliability of the Second Korean Working Conditions Survey. Saf. Health Work 2013, 4, 111-116. [CrossRef] [PubMed]

23. Simões, M.R.L.; Souza, C.; Alcantara, M.A.; Assunção, A.Á. Precarious working conditions and health of metropolitan bus drivers and conductors in Minas Gerais, Brazil. Am. J. Ind. Med. 2019, 62, 996-1006. [CrossRef] [PubMed]

24. Matilla-Santander, N.; González-Marrón, A.; Martín-Sánchez, J.C.; Lidón-Moyano, C.; Cartanyà-Hueso, À.; Martínez-Sánchez, J.M. Precarious employment and health-related outcomes in the European Union: A cross-sectional study. Crit. Public Health 2020, 30, 429-440. [CrossRef]

25. Jonsson, J.; Matilla-Santander, N.; Kreshpaj, B.; Johansson, G.; Kjellberg, K.; Burström, B.; Östergren, P.O.; Nilsson, K.; Strömdahl, S.; Orellana, C.; et al. Precarious employment and general, mental and physical health in Stockholm, Sweden: A cross-sectional study. Scand. J. Public Health 2021, 49, 228-236. [CrossRef] [PubMed]

26. Scott-Marshall, H.; Tompa, E. The health consequences of precarious employment experiences. Work 2011, 38, 369-382. [CrossRef] [PubMed]

27. Benach, J.; Vives, A.; Tarafa, G.; Delcols, C.; Muntaner, C. What should we know about precarious employment and health in 2025? Framing the agenda for the next decade of research. Int. J. Epidemiol. 2016, 45, 232-238. [CrossRef] [PubMed]

28. Park, J.; Kim, S.G.; Park, J.S.; Han, B.; Kim, K.B.; Kim, Y. Hazards and health problems in occupations dominated by aged workers in South Korea. Ann. Occup. Environ. Med. 2017, 29, 27. [CrossRef] [PubMed]

29. Dias, D.F.; Loch, M.R.; González, A.D.; Andrade, S.M.; Mesas, A.E. Insufficient free-time physical activity and occupational factors in Brazilian public school teachers. Rev. Saude Publica 2017, 51, 68. [CrossRef]

30. Bohle, P.; Quinlan, M.; Kennedy, D.; Williamson, A. Working hours, work-life conflict and health in precarious and "permanent" employment. Rev. Saude Publica 2004, 38, 19-25. [CrossRef]

31. Park, S.M.; Kim, G.U.; Kim, H.J.; Kim, H.; Chang, B.S.; Lee, C.K.; Yeom, J.S. Low handgrip strength is closely associated with chronic low back pain among women aged 50 years or older: A cross-sectional study using a national health survey. PLoS ONE 2018, 13, e0207759.

32. Cheon, Y.H.; Kim, H.O.; Suh, Y.S.; Kim, M.G.; Yoo, W.H.; Kim, R.B.; Yang, H.S.; Lee, S.I.; Park, K.S. Relationship between decreased lower extremity muscle mass and knee pain severity in both the general population and patients with knee osteoarthritis: Findings from the KNHANES V 1-2. PLoS ONE 2017, 12, e0173036. [CrossRef] [PubMed] 
33. Carrieri, V.; Novi, C.D.; Jacobs, R.; Robone, S. Insecure, sick and unhappy? Well-being consequences of temporary employment contracts. In Factors Affecting Worker Well-Being: The Impact of Change in the Labor Market; Polachek, S.W., Tatsiramos, K., Eds.; Emerald Group Publishing: Bingley, UK, 2014; pp. 157-193.

34. Jonsson, J.; Vives, A.; Benach, J.; Kjellberg, K.; Selander, J.; Johansson, G.; Bodin, T. Measuring precarious employment in Sweden: Translation, adaptation and psychometric properties of the Employment Precariousness Scale (EPRES). BMJ Open 2019,9 , e029577. [CrossRef] [PubMed] 